\title{
Structure and Reactivity of the Mo/ZSM-5 Dehydroaromatization Catalyst: An Operando Computational Study
}

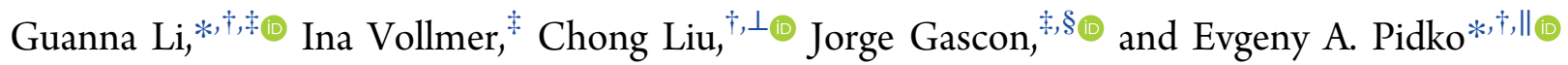 \\ ${ }^{\dagger}$ Inorganic Systems Engineering, Department Chemical Engineering and ${ }^{\ddagger}$ Catalysis Engineering, Department Chemical Engineering, \\ Delft University of Technology, 2629 HZ Delft, The Netherlands \\ ${ }^{\S}$ Advanced Catalytic Materials, KAUST Catalysis Center, King Abdullah University of Science and Technology, Thuwal 23955, \\ Saudi Arabia \\ "TheoMAT group, ITMO University, Lomonosova Street 9, St. Petersburg 191002, Russia
}

Supporting Information

ABSTRACT: Mo/ZSM-5 is one of the most studied and efficient catalysts for the dehydroaromatization of methane (MDA), but the mechanism of its operation remains controversial. Here, we combine an ab initio thermodynamic analysis with a comprehensive mechanistic density functional theory study to address Mo-speciation in the zeolite and identify the active sites under the reaction conditions. We show that the exposure of Mo/ZSM-5 to the MDA conditions yields a range of reduced sites including mono- and binuclear Mo-oxo and Mocarbide complexes. These sites can catalyze the MDA reaction via two alternative reaction

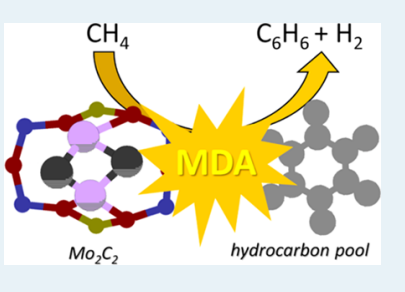
channels, namely, the $\mathrm{C}-\mathrm{C}$ coupling (ethylene) and the hydrocarbon-pool propagation mechanisms. Our calculations point toward the binuclear Mo-carbide species operating through the hydrocarbon-pool mechanism to be the most catalytically potent species. Although all other Mo sites in the activated catalyst can promote $\mathrm{C}-\mathrm{H}$ activation in methane, they fail to provide a successful path to the desirable low-molecular-weight products.

KEYWORDS: heterogeneous catalysis, zeolite, computational chemistry, methane dehydroaromatization, cooperation

\section{INTRODUCTION}

The abundant reserves of natural gas discovered globally in recent years have boosted the interest in converting methane, the primary component of natural gas, to high-value liquid chemical products. ${ }^{1}$ The traditional indirect method of methane conversion via syngas chemistry is only practical at a large natural gas field. An introduction of direct catalytic paths from natural gas to liquid (GtL) products would enable the onsite valorization of methane at a small scale. There are two main GtL strategies involving oxidative and nonoxidative conversion routes, ${ }^{2}$ with the latter offering benefits related to process control and overall efficiency. ${ }^{3}$ Nonoxidative methane dehydroaromatization (MDA) was first reported in $1989^{4}$ and has been attracting continuous attention from the industry and academia. ${ }^{5}$

Molybdenum-modified ZSM-5 zeolite is the most active catalyst for this process reported to date. ${ }^{6}$ Its practical implementation is however limited by heavy coke formation accompanying the MDA reaction. ${ }^{7}$ Despite decades of research, the nature of the active molybdenum species and the mechanism of MDA reaction remain moot. ${ }^{8}$ Most researchers agree on the importance of molecular-sized Mo (oxy)carbide $\left(\mathrm{MoO}_{x} \mathrm{C}_{y}\right)$ clusters stabilized at lattice $\left[\mathrm{AlO}_{2}\right]^{-}$ sites inside the ZSM-5 pores. The formation of the reduced $\mathrm{MoO}_{x} \mathrm{C}_{y}$ active phase from monomeric ${ }^{9}$ and dimeric ${ }^{10}$ Mo-oxo cations during the activation stage of the MDA process has been proposed. ${ }^{6 a, 11}$ The fact that the active $\mathrm{MoO}_{x} \mathrm{C}_{y}$ sites only form under the reaction conditions calls for operando characterization techniques, the application of which is particularly challenging under the very harsh conditions of the MDA process. ${ }^{9, e, 12}$ The coexistence of different Mo sites with varying geometries, nuclearities, and degrees of carburization further hampers the interpretation of the characterization data. ${ }^{13}$ Nevertheless, recent experimental studies point toward monomeric and dimeric molybdenum (oxy)carbidic species as the dominant species in the activated Mo/ZSM-5 catalyst. ${ }^{9 \mathrm{~d}, \mathrm{e}, 13 \mathrm{~b}, 14}$

Given the high heterogeneity of practical Mo/ZSM-5 catalysts and the experimental challenges associated with their characterization, there is a clear need for a systematic computational study of the behavior of this catalyst under the conditions of the catalytic process using operando modeling approaches. ${ }^{15}$ So far, there have been only a few computational works on the MDA reaction. ${ }^{16-19}$ Zhou et al. reported a density functional theory (DFT) study on the mechanism of methane dehydrogenation and ethylene formation over $\mathrm{MoC}_{x} \mathrm{H}_{y}$ species representing the carburized Mo active phase. ${ }^{16}$ The combination of a generic algorithm and DFT calculations was used to analyze the structure and location of various $\mathrm{Mo}_{2} \mathrm{C}_{x}$ and $\mathrm{Mo}_{4} \mathrm{C}_{x}$ species in the ZSM-5 zeolite. ${ }^{17}$ The adsorption strengths of $\mathrm{CH}_{x}$ species over $\mathrm{Mo}_{2} \mathrm{C}$ and $\mathrm{Mo}_{4} \mathrm{C}_{2}$ clusters were evaluated by Shetty et al. ${ }^{18}$ Reaction pathways for

Received: May 28, 2019

Revised: $\quad$ August 1, 2019

Published: August 9, 2019 

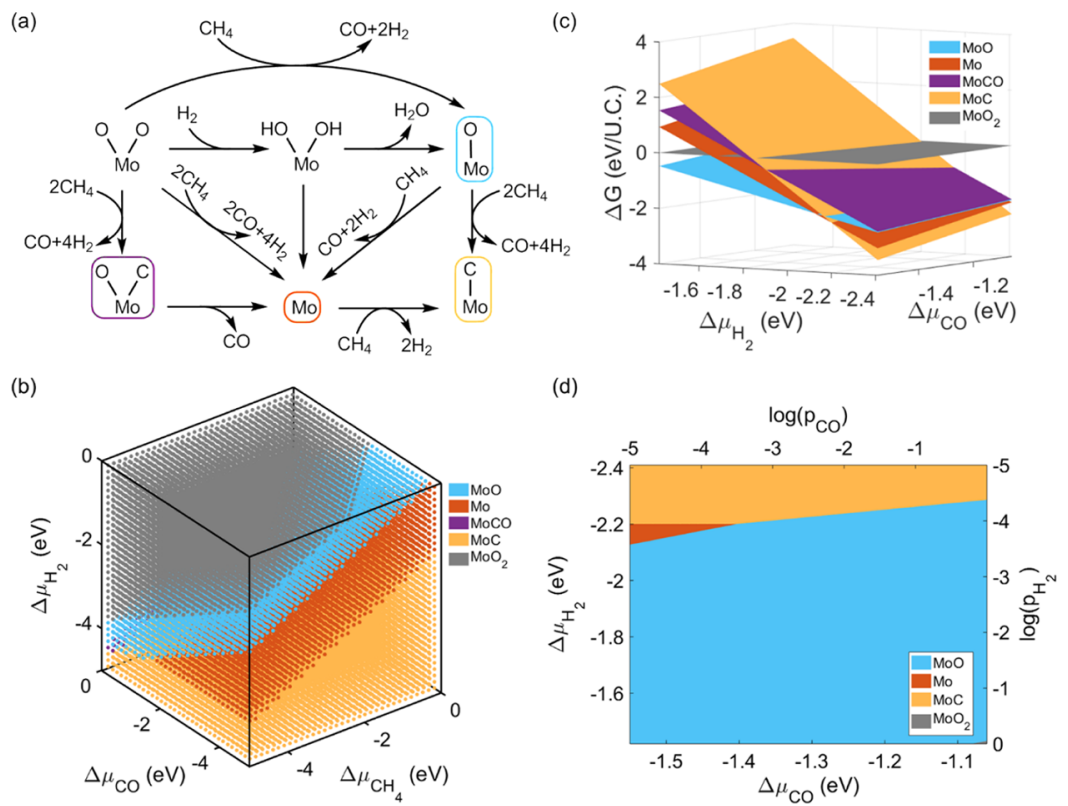

Figure 1. (a) Simplified reduction and carburization pathways of $\left[\mathrm{MoO}_{2}\right]^{2+}$ with $\mathrm{CH}_{4}$. (b) Most stable $\mathrm{MoO}_{x} \mathrm{C}_{y}$ species as a function of chemical potentials of $\mu_{\mathrm{CH}_{4}}, \mu_{\mathrm{CO}}$, and $\mu_{\mathrm{H}_{2}}$ (cf. eq 11). (c) Gibbs free energy of formation of $\mathrm{MoO}_{x} \mathrm{C}_{y}$ as a function of $\mu_{\mathrm{CO}}$ and $\mu_{\mathrm{H}_{2}}$. (d) Projection of the most stable species at a fixed $\mu_{\mathrm{CH}_{4}}$ corresponding to $p_{\mathrm{CH}_{4}}=0.95 \mathrm{~atm}$ and $T=1000 \mathrm{~K} . \mu_{\mathrm{CO}}$ and $\mu_{\mathrm{H}_{2}}$ were further converted into their partial pressures at $T$ $=1000 \mathrm{~K}$

ethylene and aromatic hydrocarbon formation over $\mathrm{Mo}_{2} \mathrm{C}_{6}$ and $\mathrm{Mo}_{4} \mathrm{C}_{2}$ species were recently proposed based on periodic DFT calculations. ${ }^{19}$ Moreover, the active site and mechanistic proposals reported so far were mostly based on the results of DFT calculations, which did not account for the conditions of the catalytic process and compositions of the reactive medium. These factors often greatly impact the active site speciation in the working zeolite catalyst. ${ }^{20}$

\section{COMPUTATIONAL DETAILS}

All spin-polarized DFT calculations were performed using the Vienna ab initio simulation package (VASP, version 5.3.5). ${ }^{21 \mathrm{a}, \mathrm{b}}$ The Perdew-Burke-Ernzerhof functional based on the generalized gradient approximation was chosen to account for the exchange-correlation energy. ${ }^{21,22}$ The kinetic energy cut-off of the plane-wave basis set was set to $500 \mathrm{eV}$. A Gaussian smearing of the population of partial occupancies with a width of $0.05 \mathrm{eV}$ was used during iterative diagonalization of the Kohn-Sham Hamiltonian. The threshold for energy convergence for each iteration was set to $10^{-5}$ $\mathrm{eV}$. Geometries were assumed to be converged when forces on each atom were less than $0.05 \mathrm{eV} / \AA$. Considering the large unit cell, Brillouin zone-sampling was restricted to the $\Gamma$ point. The van der Waals interactions were included by using Grimme's DFT-D3(BJ) method as implemented in VASP. ${ }^{23}$ The nudged-elastic-band method with the improved tangent estimate (CI-NEB) was used to determine the minimum energy path and to locate the transition state structure for each elementary reaction step. ${ }^{24}$ The Gibbs free energy was calculated under a typical reaction condition of $1000 \mathrm{~K}$ by a vibrational frequency analysis based on the harmonic normal mode approximation unless a specific clarification is given.

An $\mathrm{ab}$ initio thermodynamics (AITD) analysis was carried out to analyze the stability of the potential molybdenum (oxy)carbide species confined in the micropores of the ZSM-5 zeolite under the reaction conditions. ${ }^{25 a-c}$ In this method, the vibrational and PV contributions of solids were neglected and the Gibbs free energies of Mo-containing ZSM-5 solids were approximated as their respective electronic energies computed by DFT. The chemical potentials of the gas-phase compounds of $\mathrm{CH}_{4}, \mathrm{CO}, \mathrm{CO}_{2}$, and $\mathrm{H}_{2}$ depend on the experimental temperature $(T)$ and their corresponding partial pressures $(p)$. A detailed description of the computational methods is provided in the Supporting Information.

\section{RESULTS AND DISCUSSION}

Here, we present a comprehensive analysis of how the active Mo phase evolves under the conditions of the MDA reaction and investigate computationally its role in methane dehydrogenation and $\mathrm{C}-\mathrm{C}$ bond formation, which are the key steps of the MDA process. The starting point for our computational analysis is mononuclear $\left[\mathrm{MoO}_{2}\right]^{2+}$ and binuclear $\left[\mathrm{Mo}_{2} \mathrm{O}_{5}\right]^{2+}$ complexes in ZSM-5 pores (computational details, Figure S1, Tables S1 and S2 in the Supporting Information), which were earlier proposed to be the precursors for the active Mo phase in the MDA catalyst. ${ }^{3 a, 9 c, 10 a}$ Starting from these structures, we computationally investigated the possible reaction paths toward the reduced molybdenum (oxy)carbide species under the conditions of catalyst activation (Figures S2 and S3). Figure 1a summarizes the main possible reduction paths for $\left[\mathrm{MoO}_{2}\right]^{2+}$. The local geometries of the extraframework cationic $\mathrm{MoO}_{x} \mathrm{C}_{y}$ complexes formed are summarized in Figure S4. Condition-dependent stability assessment of the various possible configurations was carried out using the ab initio thermodynamic (AITD) analysis method, and the results are summarized in Figure $1 \mathrm{~b}, \mathrm{c}$. Figure $1 \mathrm{~b}$ presents a projection of the condition-dependent Gibbs free energies of formation, showing the most stable $\left[\mathrm{MoO}_{x} \mathrm{C}_{y}\right]^{2+}$ species as a function of temperature and the composition of the reactive gaseous phase expressed as chemical potentials $\mu_{\mathrm{CH}_{4}}, \mu_{\mathrm{CO}}$, and $\mu_{\mathrm{H}}$. It can be seen that from the top left to the bottom right, the most stable 

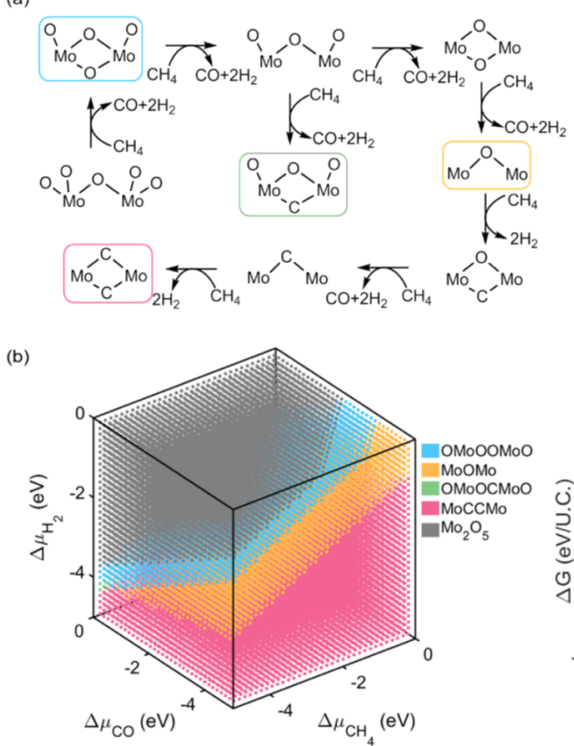
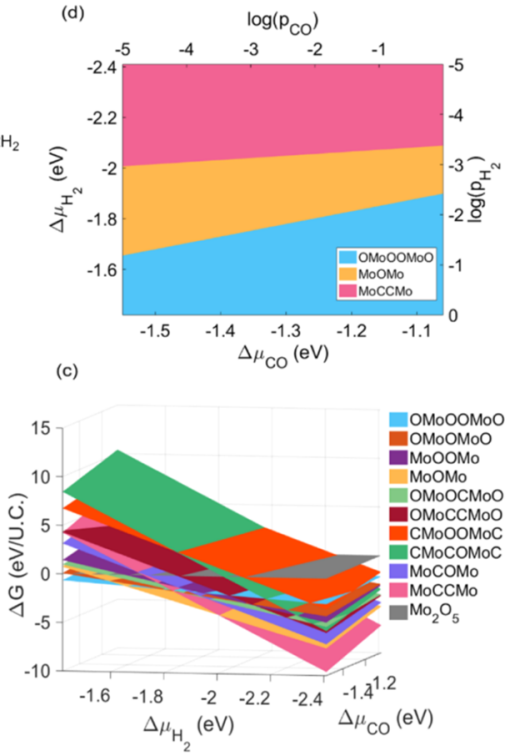

Figure 2. (a) Simplified reaction pathways of $\left[\mathrm{Mo}_{2} \mathrm{O}_{5}\right]^{2+}$ reduction and carburization by methane. (b) Most stable $\left[\mathrm{Mo}_{2} \mathrm{O}_{x} \mathrm{C}_{y}\right]^{2+}$ species as a function of chemical potentials of $\mu_{\mathrm{CH}_{4}}, \mu_{\mathrm{CO}}$, and $\mu_{\mathrm{H}_{2}}$ (cf. eq 13). (c) Gibbs free energy of formation of $\left[\mathrm{Mo}_{2} \mathrm{O}_{x} \mathrm{C}_{y}\right]^{2+}$ as a function of $\mu_{\mathrm{CO}}$ and $\mu_{\mathrm{H}_{2}}$. (d) Projection of the most stable species at a fixed $\mu_{\mathrm{CH}_{4}}$ corresponding to $p_{\mathrm{CH}_{4}}=0.95$ atm and $T=1000 \mathrm{~K}$. $\mu_{\mathrm{CO}}$ and $\mu_{\mathrm{H}_{2}}$ were further converted into their partial pressures at $T=1000 \mathrm{~K}$.

species gradually transfer from oxidic $\left[\mathrm{MoO}_{2}\right]^{2+}$ to carbidic $[\mathrm{MoC}]^{2+}$ with $[\mathrm{MoO}]^{2+}$ and $[\mathrm{Mo}]^{2+}$ being the main metastable intermediates. $[\mathrm{MoCO}]^{2+}$ species can only be stabilized within a very narrow range of condition space (at low $\mu_{\mathrm{H}}$ and $\mu_{\mathrm{CH}_{4}}$ and high $\left.\mu_{\mathrm{CO}}\right)$. The activation of Mo/ZSM-5 in $\mathrm{CH}_{4}$ flow takes place at $p_{\mathrm{CH}_{4}}=0.95$ atm and $T=1000$ $\mathrm{K}^{25,26}$ The Gibbs free energies of formation of the most stable species under these conditions $\left(\mu_{\mathrm{CH}_{4}}=-1.03\right)$ are shown in Figure $1 \mathrm{c}-\mathrm{d}$. Our data reveal that the decrease of $p_{\mathrm{H}_{2}}$ results in the destabilization of the initial $\left[\mathrm{MoO}_{2}\right]^{2+}$ cations with the concomitant stabilization of the reduced $[\mathrm{MoO}]^{2+}$, which are further carburized into $[\mathrm{MoC}]^{2+}$. The partial pressure of $\mathrm{CO}$ $\left(p_{\mathrm{CO}}\right)$ has only minor influences on the relative stability of these $\left[\mathrm{MoO}_{x} \mathrm{C}_{y}\right]^{2+}$ species. Figure S5 shows the Gibbs free energy of formation of $\left[\mathrm{MoO}_{x} \mathrm{C}_{y}\right]^{2+}$ as a function of $p_{\mathrm{H}_{2}}$ with fixed $p_{\mathrm{CH}_{4}}=0.95 \mathrm{~atm}$ and $p_{\mathrm{CO}}=0.013 \mathrm{~atm}$. Our data show that the reduced mononuclear $\left[\mathrm{MoO}_{x} \mathrm{C}_{y}\right]^{2+}$ sites are a mixture of $[\mathrm{MoO}]^{2+}$ and $[\mathrm{MoC}]^{2+}$ ions, the ratio of which depends on $p_{\mathrm{H} 2}$ under the specific conditions.

The Gibbs free energies of formation of $\left[\mathrm{MoO}_{x} \mathrm{C}_{y}\right]^{2+}$ in the atmosphere of $\mathrm{CO}$ and $\mathrm{CO}_{2}$ were also analyzed as a function of $\mu_{\mathrm{CO}}$ and $\mu_{\mathrm{CO}_{2}}$ (Figure S6). The reduction and carburization of $\left[\mathrm{MoO}_{2}\right]^{2+}$ with $\mathrm{CO}$ yields different forms of $\left[\mathrm{MoO}_{x} \mathrm{C}_{y}\right]^{2+}$, among which $[\mathrm{MoC}]^{2+}$ is the most favored thermodynamically at low $p_{\mathrm{CO}}$ and $p_{\mathrm{CO}_{2}}$, similar to the above prediction for catalyst activation in $\mathrm{CH}_{4}$. This is in line with the experimental findings that independent of the reductant, high-temperature Mo/ ZSM-5 activation yields the same Mo active phase. ${ }^{12 \mathrm{~b}}$

After identifying the most thermodynamically stable $\left[\mathrm{MoO}_{x} \mathrm{C}_{y}\right]^{2+}$ species, we assessed the kinetic feasibility of their formation by analyzing the reaction Gibbs free energies for the elementary steps of the underlying reduction and carburization processes. The results are summarized in Figures S7-S9. Our data show that the reduction process is driven by the entropy gain associated with the formation of additional $\mathrm{H}_{2}$ and $\mathrm{CO}$ molecules by the reduction of $\left[\mathrm{MoO}_{2}\right]^{2+}$ with $\mathrm{CH}_{4}$ (Figure S7). For example, the energy losses encountered at the first step of the $\mathrm{CH}_{4}$ activation stage $(\Delta G=154 \mathrm{~kJ} / \mathrm{mol})$ are compensated by over $200 \mathrm{~kJ} / \mathrm{mol}$ energy gain during the subsequent reduction of $\left[\mathrm{MoO}_{2}\right]^{2+}$ to $[\mathrm{MoO}]^{2+}$ producing gaseous $\mathrm{CO}$ and $\mathrm{H}_{2}$. The alternative reduction paths via producing $\mathrm{C}_{2} \mathrm{H}_{6}, \mathrm{C}_{2} \mathrm{H}_{4}$, and $\mathrm{H}_{2} \mathrm{O}$ are much less favorable than those producing $\mathrm{CO}$ and $\mathrm{H}_{2}$ (Figure $\mathrm{S} 8$ ), which is in line with the experiment (Figure S2). The formation of $[\mathrm{MoC}]^{2+}$ by the reaction with $\mathrm{CO}$ is also a feasible process (Figure S9).

Next, a similar computational analysis was carried out for the binuclear $\left[\mathrm{Mo}_{2} \mathrm{O}_{5}\right]^{2+}$ precursors in ZSM-5 pores. The most probable reduction paths and the associated AITD analysis results are summarized in Figure 2. We have compared the Gibbs free energies of formation of 11 different $\left[\mathrm{Mo}_{2} \mathrm{O}_{x} \mathrm{C}_{y}\right]^{2+}$ configurations (local geometries are shown in Figure S10) that potentially can be formed upon the reduction of the $\left[\mathrm{Mo}_{2} \mathrm{O}_{5}\right]^{2+}$ cations. Figure $2 \mathrm{c}, \mathrm{d}$ presents the Gibbs free energies of formation and the corresponding two-dimensional projection of the most stable species at the fixed condition of $p_{\mathrm{CH}_{4}}=0.95 \mathrm{~atm}$ and $T=1000 \mathrm{~K}$. Similar to the results of the mononuclear complexes, $p_{\mathrm{H}_{2}}$ has a significant influence on the stability of the binuclear clusters. $\left[\mathrm{Mo}_{2} \mathrm{O}_{5}\right]^{2+}$ is gradually reduced to $\left[\mathrm{Mo}_{2} \mathrm{O}\right]^{2+}$ and eventually carburized to $\left[\mathrm{Mo}_{2} \mathrm{C}_{2}\right]^{2+}$ species at low $p_{\mathrm{H}_{2}}$ (Figure S11). A similar trend is also observed for the reduction in CO (Figure S12).

The kinetic feasibility of the reduction of $\left[\mathrm{Mo}_{2} \mathrm{O}_{x} \mathrm{C}_{y}\right]^{2+}$ species was further evaluated. Figure $\mathrm{S} 13$ proposes the plausible conversion pathways for the evolution of the $\left[\mathrm{Mo}_{2} \mathrm{O}_{5}\right]^{2+}$ species by reaction with methane. $\left[\mathrm{Mo}_{2} \mathrm{O}\right]^{2+}$ and $\left[\mathrm{Mo}_{2} \mathrm{C}_{2}\right]^{2+}$ formation via carburization reactions by $\mathrm{CO}$ is thermodynamically more favorable compared to that by methane (Figure S14). The possible carburization reaction pathways with the production of $\mathrm{C}_{2} \mathrm{H}_{6}, \mathrm{C}_{2} \mathrm{H}_{4}$, and $\mathrm{H}_{2} \mathrm{O}$ were found to be thermodynamically prohibited (Figure S15), 
which is consistent with the experimental observation (Figure S2).

AITD analysis identifies mononuclear $[\mathrm{MoC}]^{2+}$ and $[\mathrm{MoO}]^{2+}$ and binuclear $\left[\mathrm{Mo}_{2} \mathrm{C}_{2}\right]^{2+}$ and $\left[\mathrm{Mo}_{2} \mathrm{O}\right]^{2+}$ as the most stable species formed during the activation stage of the MDA reaction. We next assessed the activity of these species for the catalytic MDA reaction by considering methane dehydrogenation and subsequent $\mathrm{C}-\mathrm{C}$ bond formation as model elementary processes relevant to the overall MDA process. Two mechanisms were considered (Figure 3a),

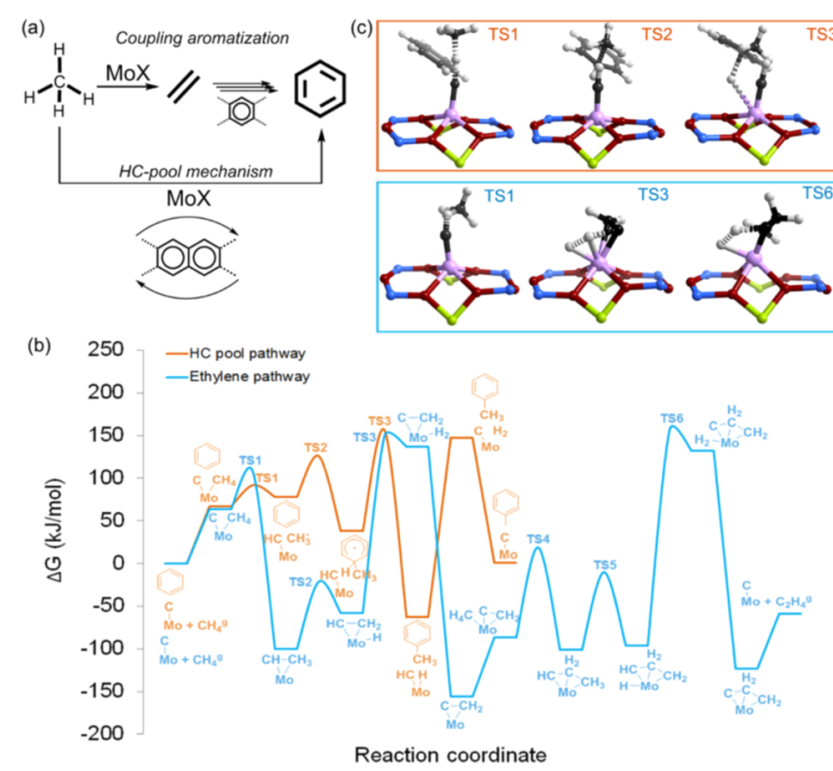

Figure 3. (a) Schematic representation of the two different reaction mechanisms of methane to aromatics via ethylene and via the hydrocarbon pool. (b) Reaction energy diagram of ethylene formation and methyl radical aggregation over the mononuclear $[\mathrm{MoC}]^{2+}$ site (Gibbs free energy was calculated at $T=1000 \mathrm{~K}$ ). (c) Local geometries of the selected transition states (TSs).

namely, the direct $\mathrm{C}-\mathrm{C}$ coupling to ethylene ${ }^{5 \mathrm{f}}$ and the radical hydrocarbon-pool mechanism, ${ }^{9,12 \mathrm{~d}}$ in which the aromatic product is proposed to be produced via the radical alkylation of a confined hydrocarbon-pool intermediate. The results are summarized in Figures $3 b-c$ and 4 for the mono- and binuclear Mo sites, respectively.

The reaction free energy diagram for ethylene formation and methyl radical recombination paths over the mononuclear $[\mathrm{MoC}]^{2+}$ species are shown in Figure $3 \mathrm{~b}$. Figure $3 \mathrm{c}$ displays the local structures of the selected transition states (TSs). The local geometries of all reaction intermediates are shown in Figure $\mathrm{S} 16 . \mathrm{CH}_{4}$ adsorption at the active site is endergonic by $64 \mathrm{~kJ} / \mathrm{mol}$. The subsequent $\mathrm{C}-\mathrm{H}$ bond cleavage is strongly exergonic $(\Delta G=-164 \mathrm{~kJ} / \mathrm{mol})$ and proceeds with a barrier of only $43 \mathrm{~kJ} / \mathrm{mol}$. Further dehydrogenation of the $\mathrm{CH}_{3}$ moiety to $\mathrm{CH}_{2}$ needs to overcome only a barrier of $79 \mathrm{~kJ} / \mathrm{mol}$. The most difficult reaction step then is the formation of the $\mathrm{H}_{2}$ molecule and the $\left[\mathrm{MoC}_{2} \mathrm{H}_{2}\right]^{2+}$ site with a barrier of $208 \mathrm{~kJ} /$ mol. The subsequent desorption of $\mathrm{H}_{2}$ provides a very substantial stabilization to the system. Activation of a second $\mathrm{CH}_{4}$ molecule over the $\left[\mathrm{MoC}_{2} \mathrm{H}_{2}\right]^{2+}$ intermediate proceeds with a barrier of $106 \mathrm{~kJ} / \mathrm{mol}$, followed by a favorable dehydrogenation of the second $\mathrm{CH}_{3}$ group to $\mathrm{CH}_{2}$. Further dehydrogenation to form $\mathrm{H}_{2}$ is again the most energydemanding step. Once $\mathrm{H}_{2}$ is formed, ethylene can be desorbed

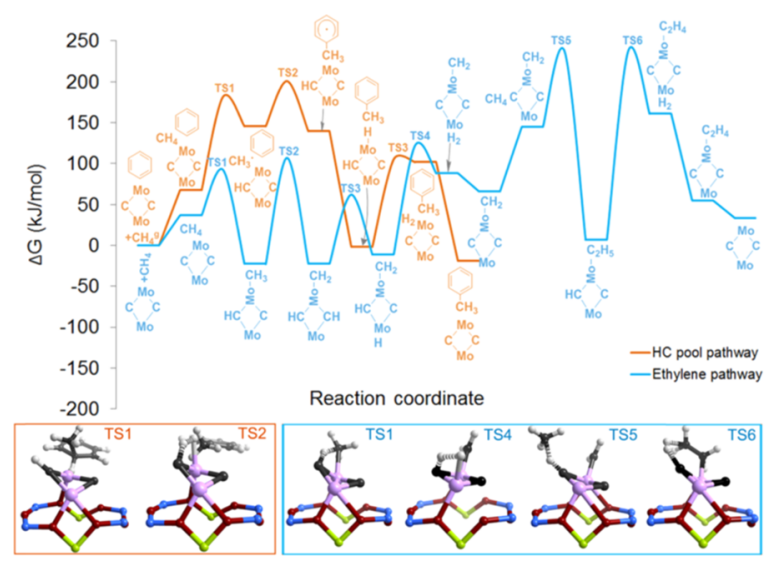

Figure 4. Reaction energy diagram of ethylene formation and methyl radical aggregation over the binuclear $\left[\mathrm{Mo}_{2} \mathrm{C}_{2}\right]^{2+}$ site and the local geometries of the selected transition states (Gibbs free energy was calculated at $T=1000 \mathrm{~K}$ ).

from the Mo site via a barrier of only $64 \mathrm{~kJ} / \mathrm{mol}$. The alternative hydrocarbon-pool reaction pathway initiates by a homolytic methane $\mathrm{C}-\mathrm{H}$ cleavage with a barrier of $25 \mathrm{~kJ} / \mathrm{mol}$ to form a $\mathrm{CH}_{3}$ radical and a $[\mathrm{MoCH}]^{2+}$ moiety. Next, the hydrocarbon-pool compound (represented here by a confined benzene molecule) is methylated with a barrier of $48 \mathrm{~kJ} / \mathrm{mol}$ to yield a $\sigma$-complex $\mathrm{C}_{7} \mathrm{H}_{9}{ }^{\circ}$. Subsequent dehydrogenation of $[\mathrm{HMoCH}]^{2+}$ to produce a $\mathrm{H}_{2}$ molecule has a high barrier of $210 \mathrm{~kJ} / \mathrm{mol}$. By desorption of the $\mathrm{H}_{2}$ molecule, the initial $[\mathrm{MoC}]^{2+}$ active site is regenerated and the hydrocarbon pool is propagated. The current results suggest that the cooperative hydrocarbon-pool methylation path is more energetically favorable than the mechanism via ethylene formation. The high barriers for $\mathrm{Mo}-\mathrm{CH}_{x}$ dehydrogenation suggest that they are unlikely to be involved in the catalytic process. We also evaluated the activity of the $[\mathrm{MoO}]^{2+}$ site toward methane dehydrogenation (Figures S17 and S18). Our calculations show that both ethylene formation and hydrocarbon-pool propagation paths over $[\mathrm{MoO}]^{2+}$ are much more energetically demanding compared to the $[\mathrm{MoC}]^{2+}$ active site.

Methane activation by binuclear $\left[\mathrm{Mo}_{2} \mathrm{C}_{2}\right]^{2+}$ and $\left[\mathrm{Mo}_{2} \mathrm{O}\right]^{2+}$ sites was also investigated (Figures 4 and S19-S21). Heterolytic dissociation of the first methane is exergonic with a barrier of $55 \mathrm{~kJ} / \mathrm{mol}$ and a reaction free energy of -60 $\mathrm{kJ} / \mathrm{mol}$. The second dehydrogenation reaction from $\mathrm{CH}_{3}$ to $\mathrm{CH}_{2}$ shows an activation barrier of $130 \mathrm{~kJ} / \mathrm{mol}$. The migration of the $\mathrm{H}$ atom between $\mathrm{C}$ and Mo sites is a relatively easy process, and the recombination of two $\mathrm{H}$ atoms to form a $\mathrm{H}_{2}$ molecule needs to overcome a barrier of $133 \mathrm{~kJ} / \mathrm{mol}$ in this case. The activation barrier for the second methane activation by $\left[\mathrm{Mo}_{2} \mathrm{C}_{2} \mathrm{H}_{2}\right]^{2+}$ is $93 \mathrm{~kJ} / \mathrm{mol}$. The reaction is endergonic by $-138 \mathrm{~kJ} / \mathrm{mol}$. The subsequent $\mathrm{C}_{2} \mathrm{H}_{5}$ dehydrogenation and $\mathrm{H}_{2}$ molecule formation is the most difficult reaction step with an activation barrier of $231 \mathrm{~kJ} / \mathrm{mol}$. The active site is regenerated and the catalytic cycle is closed after ethylene desorption. Compared to the heterolytic $\mathrm{C}-\mathrm{H}$ bond dissociation, the homolytic methane activation is energetically less favorable. The computed barrier for $\mathrm{CH}_{3}$ radical formation is $114 \mathrm{~kJ} / \mathrm{mol}$ and the reaction energy is $78 \mathrm{~kJ} / \mathrm{mol}$. The barrier for the subsequent $\mathrm{C}-\mathrm{C}$ bond formation between the $\mathrm{CH}_{3}$ radical and the model hydrocarbon-pool compound is only $55 \mathrm{~kJ} / \mathrm{mol}$. The $\mathrm{H}$-transfer from $\mathrm{C}_{7} \mathrm{H}_{9}{ }^{\bullet} \sigma$-complex back to the Mo cluster is a barrierless process that stabilizes the system by $-142 \mathrm{~kJ} /$ 
mol. The next step of dehydrogenation and $\mathrm{H}_{2}$ formation is endergonic $(104 \mathrm{~kJ} / \mathrm{mol})$ with an activation barrier of $107 \mathrm{~kJ} /$ mol. Figures S18 and S19 show that both ethylene formation and hydrocarbon-pool reaction pathways over the $\left[\mathrm{Mo}_{2} \mathrm{O}\right]^{2+}$ site are energetically much less favorable compared to those over the $\left[\mathrm{Mo}_{2} \mathrm{C}_{2}\right]^{2+}$ site.

Based on these reactivity results, we propose that molybdenum carbides are more active than the reduced molybdenum-oxo species for the catalytic MDA reaction. The dehydrogenated reaction intermediates over Mo-oxo sites are generally much less stable compared to those over their Mocarbide counterparts. The overall reaction barriers over Mooxo sites are prohibitively high $(>350 \mathrm{~kJ} / \mathrm{mol})$, whereas those over $\mathrm{MoC}$ and $\mathrm{Mo}_{2} \mathrm{C}_{2}$ are below 200 and $250 \mathrm{~kJ} / \mathrm{mol}$, respectively (Figures $3 \mathrm{~b}$ vs S16, and Figures 4 vs S18). These reactivity differences are attributed to the distinct electronic properties between Mo-oxo and Mo-carbidic species (Figure S20). We also conclude that the binuclear $\left[\mathrm{Mo}_{2} \mathrm{C}_{2}\right]^{2+}$ site is a more likely candidate for the active sites responsible for the growth of aromatic products upon methane activation (Figure $\mathrm{S} 21)$. The reaction intermediates over such a $\left[\mathrm{Mo}_{2} \mathrm{C}_{2}\right]^{2+}$ site are not too stable to become "resting states," inhibiting subsequent reactions from occurring over them. The alternative $[\mathrm{MoC}]^{2+}$ site tends to form extremely stable $\mathrm{CH}_{x}$ complexes, which are likely to be the off-cycle intermediates and potential sites of excessive accumulation of unreactive coke. We also identify the hydrocarbon pool-like radical reaction pathway to be more energetically favorable than the alternative Mo-only ethylene production path. The radical path involves methane activation over $\mathrm{MoC}_{x}$, which act cooperatively with the neighboring confined aromatic species to form $\mathrm{C}-\mathrm{C}$ bonds and ultimately generate the desirable aromatic products via cracking.

Previous experimental results showed that the $\mathrm{Mo}^{6+}$-oxo species are not active for the production of ethylene or aromatics. These products are only observed after the activation period, during which the carburized Mo species are formed. ${ }^{2 b, 3 a, 7 b}$ Furthermore, bulk $\mathrm{MoO}_{3}$ and $\mathrm{MoO}_{2}$ are not stable under the reaction conditions and transform into $\mathrm{MoC}_{x}$ whereas $\mathrm{Mo}^{4+}$-oxo species can only exist as very small clusters/ complexes. $^{27}$ XANES measurements further suggest Mocarbide-type species as the dominant phase present under the reactive conditions and to be responsible for the methane dehydroaromatization activity of Mo/ZSM-5. ${ }^{9 \mathrm{~d}, 12 \mathrm{~d}, 28}$ It is proposed that the confined polyaromatic carbon species next to the $\mathrm{MoC}_{x}$ species is of importance for benzene formation. However, the structure of such a reactive hydrocarbon-pool species and the exact mechanism of their cooperative action during methane-to-benzene conversion require further dedicated analyses. Further dedicated operando experimental studies with high space and time resolution are desirable to validate and additionally support the current mechanistic and active site proposals. Spectroscopic techniques such as operando X-ray absorption spectroscopy, Mo-NMR, EPR, Raman, and FTIR combined with computational modeling and transient kinetic methods suitable for tracking the evolution of the active site could provide the necessary crucial information on the MDA reaction mechanism and active site speciation in the working Mo/ZSM-5 catalyst. ${ }^{13 a, 29}$

\section{CONCLUSIONS}

In conclusion, the evolution of molybdenum-oxo species and the structures of the reduced molybdenum (oxy) carbide complexes at the initial activation stage of the MDA reaction were investigated. The results demonstrate that reduced Mooxo and carburized Mo-carbide species represent thermodynamically the most stable species generated during the MDA activation period. The reactivity study indicates that Mocarbide species are generally more reactive than the reduced Mo-oxo complexes. Our calculations point toward the important role of the cooperation between the binuclear $\left[\mathrm{Mo}_{2} \mathrm{C}_{2}\right]^{2+}$ carbide cations and confined aromatic species, which provide the most favorable channel for nonoxidative methane activation.

\section{ASSOCIATED CONTENT}

S Supporting Information

The Supporting Information is available free of charge on the ACS Publications website at DOI: 10.1021/acscatal.9b02213.

Computational details, phase diagrams under the condition of $\mathrm{CO}$ feeding, reduction and carburization pathways from initial $\mathrm{MoO}_{2}$ and $\mathrm{Mo}_{2} \mathrm{O}_{5}$ species, all local geometries of the reaction intermediates over $\mathrm{MoC}_{x}$ species, ethylene and hydrocarbon-pool mechanism study over $\mathrm{MoO}$ and $\mathrm{Mo}_{2} \mathrm{O}_{2}$ species, density of states, and orbital analysis (PDF)

\section{AUTHOR INFORMATION}

\section{Corresponding Authors}

*E-mail: g.li-2@tudelft.nl (G.L.).

*E-mail: e.a.pidko@tudelft.nl (E.A.P.).

ORCID

Guanna Li: 0000-0003-3031-8119

Chong Liu: 0000-0003-0311-8744

Jorge Gascon: 0000-0001-7558-7123

Evgeny A. Pidko: 0000-0001-9242-9901

\section{Present Address}

${ }^{\perp}$ Institute for Catalysis, Hokkaido University, Sapporo 0010021, Japan (C.L.).

\section{Author Contributions}

The manuscript was written through contributions of all authors. All authors have given approval to the final version of the manuscript.

\section{Notes}

The authors declare no competing financial interest.

\section{ACKNOWLEDGMENTS}

This work was financially supported by NWO veni grant (no. 016.Veni.172.034). NWO surfsara is acknowledged for providing access to the supercomputer facilities. Partial support from the Ministry of education and Science of the Russian Federation (Project 11.1706.2017/4.6) is acknowledged.

\section{REFERENCES}

(1) (a) Olivos-Suarez, A. I.; Szécsényi, À.; Hensen, E. J. M.; RuizMartinez, J.; Pidko, E. A.; Gascon, J. Strategies for the Direct Catalytic Valorization of Methane Using Heterogeneous Catalysis: Challenges and Opportunities. ACS Catal. 2016, 6, 2965-2981. (b) Schwach, P.; Pan, X.; Bao, X. Direct Conversion of Methane to Value-Added Chemicals over Heterogeneous Catalysts: Challenges and Prospects. Chem. Rev. 2017, 117, 8497-8520. (c) Bao, J.; Yang, G.; Yoneyama, Y.; Tsubaki, N. Significant Advances in $\mathrm{C}_{1}$ Catalysis: Highly Efficient Catalysts and Catalytic Reactions. ACS Catal. 2019, 3026-3053.

(2) (a) Ismagilov, Z. R.; Matus, E. V.; Tsikoza, L. T. Direct conversion of methane on Mo/ZSM-5 catalysts to produce benzene 
and hydrogen: achievements and perspectives. Energy Environ. Sci. 2008, 1, 526-541. (b) Tang, P.; Zhu, Q.; Wu, Z.; Ma, D. Methane activation: the past and future. Energy Environ. Sci. 2014, 7, 25802591

(3) (a) Ma, S.; Guo, X.; Zhao, L.; Scott, S.; Bao, X. Recent progress in methane dehydroaromatization: From laboratory curiosities to promising technology. J. Energy Chem. 2013, 22, 1-20. (b) Shih, C. F.; Zhang, T.; Li, J.; Bai, C. Powering the Future with Liquid Sunshine. Joule 2018, 2, 1925-1949. (c) Guo, X.; Fang, G.; Li, G.; Ma, H.; Fan, H.; Yu, L.; Ma, C.; Wu, X.; Deng, D.; Wei, M.; Tan, D.; Si, R.; Zhang, S.; Li, J.; Sun, L.; Tang, Z.; Pan, X.; Bao, X. Direct, Nonoxidative Conversion of Methane to Ethylene, Aromatics, and Hydrogen. Science 2014, 344, 616-619.

(4) Bragin, O. V.; Vasina, T. V.; Preobrazhenskii, A. V.; Minachev, K. M. Aromatization of methane on pentasil-containing catalysts. Bull. Acad. Sci. USSR, Div. Chem. Sci. 1989, 38, 680.

(5) (a) Wang, L.; Tao, L.; Xie, M.; Xu, G.; Huang, J.; Xu, Y. Dehydrogenation and aromatization of methane under non-oxidizing conditions. Catal. Lett. 1993, 21, 35-41. (b) Ding, W.; Li, S.; Meitzner, G. D.; Iglesia, E. Methane conversion to aromatics on Mo/ H-ZSM5: structure of molybdenum species in working catalysts. J. Phys. Chem. $B$ 2001, 105, 506-513. (c) Wang, H. X.; Su, L. L.; Zhuang, J. Q.; Tan, D. L.; Xu, Y. D.; Bao, X. H. Post-steam-treatment of Mo/HZSM-5 catalysts: An alternative and effective approach for enhancing their catalytic performances of methane dehydroaromatization. J. Phys. Chem. B 2003, 107, 12964-12972. (d) Zheng, H.; Ma, D.; Liu, X. M.; Zhang, W. P.; Han, X. W.; Xu, Y. D.; Bao, X. H. Methane dehydroaromatization over Mo/HZSM-5: A study of catalytic process. Catal. Lett. 2006, 111, 111-114. (e) Sarioglan, A.; Savasci, O. T.; Erdem-Senatalar, A.; Tuel, A.; Sapaly, G.; Ben Taarit, Y. The effect of support morphology on the activity of HZSM-5supported molybdenum catalysts for the aromatization of methane. J. Catal. 2007, 246, 35-39. (f) Spivey, J. J.; Hutchings, G. Catalytic aromatization of methane. Chem. Soc. Rev. 2014, 43, 792-803. (g) Sun, K.; Ginosar, D. M.; He, T.; Zhang, Y.; Fan, M.; Chen, R. Progress in Nonoxidative Dehydroaromatization of Methane in the Last 6 Years. Ind. Eng. Chem. Res. 2018, 57, 1768-1789. (h) Morejudo, S. H.; Zanon, R.; Escolastico, S.; Yuste-Tirados, I.; Malerod-Fjeld, H.; Vestre, P. K.; Coors, W. G.; Martinez, A.; Norby, T.; Serra, J. M.; Kjolseth, C. Direct conversion of methane to aromatics in a catalytic co-ionic membrane reactor. Science 2016, 353, 563-566. (i) Rahman, M.; Sridhar, A.; Khatib, S. J. Impact of the presence of Mo carbide species prepared ex situ in Mo/HZSM-5 on the catalytic properties in methane aromatization. Appl. Catal. A 2018, 558, 67-80. (j) Kumar, A.; Song, K.; Liu, L.; Han, Y.; Bhan, A. Absorptive Hydrogen Scavenging for Enhanced Aromatics Yield During Non-oxidative Methane Dehydroaromatization on $\mathrm{Mo} / \mathrm{H}-$ ZSM-5 Catalysts. Angew. Chem., Int. Ed. 2018, 57, 15577-15582. (k) Cao, Z.; Jiang, H.; Luo, H.; Baumann, S.; Meulenberg, W. A.; Assmann, J.; Mleczko, L.; Liu, Y.; Caro, J. Natural Gas to Fuels and Chemicals: Improved Methane Aromatization in an OxygenPermeable Membrane Reactor. Angew. Chem., Int. Ed. 2013, 52, 13794-13797.

(6) (a) Zheng, H.; Ma, D.; Bao, X.; Hu, J. Z.; Kwak, J. H.; Wang, Y.; Peden, C. H. F. Direct Observation of the Active Center for Methane Dehydroaromatization Using an Ultrahigh Field 95Mo NMR Spectroscopy. J. Am. Chem. Soc. 2008, 130, 3722-3723. (b) Wang, D. J.; Lunsford, J. H.; Rosynek, M. P. Catalytic conversion of methane to benzene over Mo/ZSM-5. Top. Catal. 1996, 3, 289-297. (c) Wang, D.; Lunsford, J. H.; Rosynek, M. P. Characterization of a Mo/ZSM-5 Catalyst for the Conversion of Methane to Benzene. J. Catal. 1997, 169, 347-358. (d) Weckhuysen, B. M.; Wang, D.; Rosynek, M. P.; Lunsford, J. H. Conversion of Methane to Benzene over Transition Metal Ion ZSM-5 Zeolites: I. Catalytic Characterization. J. Catal. 1998, 175, 338-346.

(7) (a) Weckhuysen, B. M.; Rosynek, M. P.; Lunsford, J. H. Characterization of surface carbon formed during the conversion of methane to benzene over Mo/H-ZSM-5 catalysts. Catal. Lett. 1998, 52, 31-36. (b) Song, Y.; Xu, Y.; Suzuki, Y.; Nakagome, H.; Zhang, Z.-
G. A clue to exploration of the pathway of coke formation on Mo/ HZSM-5 catalyst in the non-oxidative methane dehydroaromatization at 1073 K. Appl. Catal., A 2014, 482, 387-396. (c) Han, S. J.; Kim, S. K.; Hwang, A.; Kim, S.; Hong, D.-Y.; Kwak, G.; Jun, K.-W.; Kim, Y. T. Non-oxidative dehydroaromatization of methane over Mo/H-ZSM-5 catalysts: A detailed analysis of the reaction-regeneration cycle. Appl. Catal., B 2019, 241, 305-318. (d) Kosinov, N.; Coumans, F.; Uslamin, E.; Kapteijn, F.; Hensen, E. J. M. Selective Coke Combustion by Oxygen Pulsing During Mo/ZSM-5-Catalyzed Methane Dehydroaromatization. Angew. Chem., Int. Ed. 2016, 55, 15086-15090.

(8) Xu, Y.; Lin, L. Recent advances in methane dehydroaromatization over transition metal ion-modified zeolite catalysts under non-oxidative conditions. Appl. Catal., A 1999, 188, 53-67.

(9) (a) Ma, D.; Han, X.; Zhou, D.; Yan, Z.; Fu, R.; Xu, Y.; Bao, X.; $\mathrm{Hu}, \mathrm{H}$.; Au-Yeung, S. C. F. Towards Guest-Zeolite Interactions: An NMR Spectroscopic Approach. Chem. - Eur. J. 2002, 8, 4557-4561. (b) Ma, D.; Zhu, Q.; Wu, Z.; Zhou, D.; Shu, Y.; Xin, Q.; Xu, Y.; Bao, $\mathrm{X}$. The synergic effect between Mo species and acid sites in Mo/ HMCM-22 catalysts for methane aromatization. Phys. Chem. Chem. Phys. 2005, 7, 3102-3109. (c) Gao, J.; Zheng, Y. T.; Jehng, J. M.; Tang, Y. D.; Wachs, I. E.; Podkolzin, S. G. Identification of molybdenum oxide nanostructures on zeolites for natural gas conversion. Science 2015, 348, 686-690. (d) Lezcano-González, I.; Oord, R.; Rovezzi, M.; Glatzel, P.; Botchway, S. W.; Weckhuysen, B. M.; Beale, A. M. Molybdenum Speciation and its Impact on Catalytic Activity during Methane Dehydroaromatization in Zeolite ZSM-5 as Revealed by Operando X-Ray Methods. Angew. Chem., Int. Ed. 2016, 55, 5215-5219. (e) Kosinov, N.; Wijpkema, A. S. G.; Uslamin, E.; Rohling, R.; Coumans, F. J. A. G.; Mezari, B.; Parastaev, A.; Poryvaev, A. S.; Fedin, M. V.; Pidko, E. A.; Hensen, E. J. M. Confined Carbon Mediating Dehydroaromatization of Methane over Mo/ZSM-5. Angew. Chem., Int. Ed. 2018, 57, 1016-1020.

(10) (a) Borry, R. W.; Kim, Y. H.; Huffsmith, A.; Reimer, J. A.; Iglesia, E. Structure and Density of Mo and Acid Sites in MoExchanged H-ZSM5 Catalysts for Nonoxidative Methane Conversion. J. Phys. Chem. B 1999, 103, 5787-5796. (b) Li, W.; Meitzner, G. D.; Borry, R. W.; Iglesia, E. Raman and X-Ray Absorption Studies of Mo Species in Mo/H-ZSM5 Catalysts for Non-Oxidative CH4 Reactions. J. Catal. 2000, 191, 373-383.

(11) Xu, Y.; Bao, X.; Lin, L. Direct conversion of methane under nonoxidative conditions. J. Catal. 2003, 216, 386-395.

(12) (a) Ma, D.; Shu, Y. Y.; Zhang, W. P.; Han, X. W.; Xu, Y. D.; Bao, X. H. In situ H-1 MAS NMR spectroscopic observation of proton species on a Mo-modified HZSM-5 zeolite catalyst for the dehydroaromatization of methane. Angew. Chem., Int. Ed. 2000, 39, 2928-2931. (b) Vollmer, I.; van der Linden, B.; Ould-Chikh, S.; Aguilar-Tapia, A.; Yarulina, I.; Abou-Hamad, E.; Sneider, Y. G.; Olivos Suarez, A. I.; Hazemann, J.-L.; Kapteijn, F.; Gascon, J. On the dynamic nature of Mo sites for methane dehydroaromatization. Chem. Sci. 2018, 9, 4801-4807. (c) Agote-Arán, M.; Kroner, A. B.; Islam, H. U.; Sławiński, W. A.; Wragg, D. S.; Lezcano-González, I.; Beale, A. M. Determination of Molybdenum Species Evolution during NonOxidative Dehydroaromatization of Methane and its Implications for Catalytic Performance. ChemCatChem 2019, 11, 473-480. (d) Kosinov, N.; Uslamin, E. A.; Meng, L.; Parastaev, A.; Liu, Y.; Hensen, E. J. M. Reversible Nature of Coke Formation on Mo/ZSM5 Methane Dehydroaromatization Catalysts. Angew. Chem., Int. Ed. 2019, 58, 7068-7072.

(13) (a) Vollmer, I.; Yarulina, I.; Kapteijn, F.; Gascon, J. Progress in Developing a Structure-Activity Relationship for the Direct Aromatization of Methane. ChemCatChem 2019, 11, 39-52. (b) Vollmer, I.; Kosinov, N.; Szécsényi, Á.; Li, G.; Yarulina, I.; Abou-Hamad, E.; Gurinov, A.; Ould-Chikh, S.; Aguilar-Tapia, A.; Hazemann, J.-L.; Pidko, E.; Hensen, E.; Kapteijn, F.; Gascon, J. A sitesensitive quasi-in situ strategy to characterize Mo/HZSM-5 during activation. J. Catal. 2019, 370, 321-331. (c) Ma, D.; Zhang, W.; Shu, Y.; Liu, X.; Xu, Y.; Bao, X. MAS NMR, ESR and TPD studies of Mo/ 
HZSM- 5 catalysts: evidence for the migration of molybdenum species into the zeolitic channels. Catal. Lett. 2000, 66, 155-160.

(14) Kosinov, N.; Coumans, F. J. A. G.; Uslamin, E. A.; Wijpkema, A. S. G.; Mezari, B.; Hensen, E. J. M. Methane Dehydroaromatization by Mo/HZSM-5: Mono- or Bifunctional Catalysis? ACS Catal. 2017, 7, 520-529.

(15) Grajciar, L.; Heard, C. J.; Bondarenko, A. A.; Polynski, M. V.; Meeprasert, J.; Pidko, E. A.; Nachtigall, P. Towards operando computational modeling in heterogeneous catalysis. Chem. Soc. Rev. 2018, 47, 8307-8348.

(16) (a) Xing, S.; Zhou, D.; Cao, L.; Li, X. Density Functional Theory Study on Structure of Molybdenum Carbide and Catalytic Mechanism for Methane Activation over ZSM-5 Zeolite. Chin. J. Catal. 2010, 31, 415-422. (b) Zhou, D.; Zuo, S.; Xing, S. Methane Dehydrogenation and Coupling to Ethylene over a Mo/HZSM-5 Catalyst: A Density Functional Theory Study. J. Phys. Chem. C 2012, 116, 4060-4070. (c) Zhou, D.; Zhang, Y.; Zhu, H.; Ma, D.; Bao, X. The Structure, Stability, and Reactivity of Mo-oxo Species in H-ZSM5 Zeolites: Density Functional Theory Study. J. Phys. Chem. C 2007, 111, 2081-2091. (d) Zhou, D.; Ma, D.; Wang, Y.; Liu, X.; Bao, X. Study with density functional theory method on methane $\mathrm{C}-\mathrm{H}$ bond activation on the $\mathrm{MoO}_{2} / \mathrm{HZSM}-5$ active center. Chem. Phys. Lett. 2003, 373, 46-51. (e) Zhou, D.; Ma, D.; Liu, X.; Bao, X. Study with density functional theory method on methane dehydro-aromatization over Mo/HZSM-5 catalysts I: Optimization of active Mo species bonded to ZSM-5 zeolite. J. Chem. Phys. 2001, 114, 9125-9129.

(17) Gao, J.; Zheng, Y. T.; Fitzgerald, G. B.; de Joannis, J.; Tang, Y. D.; Wachs, I. E.; Podkolzin, S. G. Structure of Mo2Cx and Mo4Cx), Molybdenum Carbide Nanoparticles and Their Anchoring Sites on ZSM-5 Zeolites. J. Phys. Chem. C 2014, 118, 4670-4679.

(18) Shetty, S.; Sivakumar, S.; Jana, S. K.; Sreenivasarao, G. Investigation of $\mathrm{CHx}(\mathrm{x}=2-4)$ Adsorption on Mo2C and Mo4C2 Sites Incorporated in ZSM-5 Zeolite Using Periodic-DFT Approach. Catal. Lett. 2018, 148, 68-78.

(19) Yin, F.; Li, M.-R.; Wang, G.-C. Periodic density functional theory analysis of direct methane conversion into ethylene and aromatic hydrocarbons catalyzed by Mo4C2/ZSM-5. Phys. Chem. Chem. Phys. 2017, 19, 22243-22255.

(20) Li, G.; Pidko, E. A. The Nature and Catalytic Function of Cation Sites in Zeolites: a Computational Perspective. ChemCatChem 2019, 11, 134-156.

(21) (a) Kresse, G.; Furthmüller, J. Efficient iterative schemes for ab initio total-energy calculations using a plane-wave basis set. Phys. Rev. B 1996, 54, 11169-11186. (b) Kresse, G.; Joubert, D. From ultrasoft pseudopotentials to the projector augmented-wave method. Phys. Rev. B 1999, 59, 1758-1775.

(22) Perdew, J. P.; Burke, K.; Ernzerhof, M. Generalized Gradient Approximation Made Simple. Phys. Rev. Lett. 1996, 77, 3865-3868.

(23) Grimme, S.; Ehrlich, S.; Goerigk, L. Effect of the damping function in dispersion corrected density functional theory. J. Comput. Chem. 2011, 32, 1456-1465.

(24) Henkelman, G.; Uberuaga, B. P.; Jónsson, H. A climbing image nudged elastic band method for finding saddle points and minimum energy paths. J. Chem. Phys. 2000, 113, 9901-9904.

(25) (a) Reuter, K.; Scheffler, M. Composition and structure of the $\mathrm{RuO}_{2}(110)$ surface in an $\mathrm{O}_{2}$ and $\mathrm{CO}$ environment: Implications for the catalytic formation of $\mathrm{CO}_{2}$. Phys. Rev. B 2003, 68, No. 045407. (b) Li, G.; Vassilev, P.; Sanchez-Sanchez, M.; Lercher, J. A.; Hensen, E. J. M.; Pidko, E. A. Stability and reactivity of copper oxo-clusters in ZSM-5 zeolite for selective methane oxidation to methanol. J. Catal. 2016, 338, 305-312. (c) Paolucci, C.; Parekh, A. A.; Khurana, I.; Di Iorio, J. R.; Li, H.; Albarracin Caballero, J. D.; Shih, A. J.; Anggara, T.; Delgass, W. N.; Miller, J. T.; Ribeiro, F. H.; Gounder, R.; Schneider, W. F. Catalysis in a Cage: Condition-Dependent Speciation and Dynamics of Exchanged Cu Cations in SSZ-13 Zeolites. J. Am. Chem. Soc. 2016, 138, 6028-6048.

(26) Kosinov, N.; Coumans, F.; Li, G.; Uslamin, E.; Mezari, B.; Wijpkema, A. S. G.; Pidko, E. A.; Hensen, E. J. M. Stable Mo/HZSM-
5 methane dehydroaromatization catalysts optimized for hightemperature calcination-regeneration. J. Catal, 2017, 346, 125-133.

(27) Vollmer, I.; Kosinov, N.; Szécsényi, A.; Li, G.; Yarulina, I.; Abou-Hamad, E.; Gurinov, A.; Ould-Chikh, S.; Aguilar-Tapia, A.; Hazemann, J.-L.; et al. A site-sensitive quasi-in situ strategy to characterize Mo/HZSM-5 during activation. J. Catal. 2019, 370, 321331.

(28) Savinelli, R. O.; Scott, S. L. Wavelet transform EXAFS analysis of mono- and dimolybdate model compounds and a Mo/HZSM-5 dehydroaromatization catalyst. Phys. Chem. Chem. Phys. 2010, 12, $5660-5667$.

(29) Kosinov, N.; Liu, C.; Hensen, E. J. M.; Pidko, E. A. Engineering of Transition Metal Catalysts Confined in Zeolites. Chem. Mater. 2018, 30, 3177-3198. 